\title{
FEATURES OF THE RECOVERY OF HIGH CARBON STEEL PRODUCTS USING THE DIRECTED ENERGY DEPOSITION PROCESS
}

\author{
Sergei IGOSHIN, Dmitriy MASAYLO, Alexey ORLOV, Evgenii GYULIHANDANOV \\ Peter the Great St. Petersburg Polytechnic University, St. Petersburg, Russian Federation, \\ sergei.igosshin@gmail.com, dmasaylo@gmail.com, orlov alexey88@mail.ru, bogomolova ev@spbstu.ru
}

https://doi.org/10.37904/metal.2019.853

\begin{abstract}
All metal products that operate under high loading conditions are subject to wear over time. Therefore, there is a need to restore the geometric shape of the working parts after the consumption of the product life. For each material from which the product is made, special repair conditions are needed. There are many defects that can appear during the repair process, for example: cold and hot cracks, delamination and cavities. This article explores the possibility of repair using the DED process of the working part of the stamp from high carbon steel grade SKD11. Restoration of the worn area was carried out by surfacing the powder die tool steel H13. The results of the study of the structure and hardness in the repair zone are presented. It is shown that the obtained values are sufficient for this type of product, which indicates the successful restoration of a worn section of a high carbon steel product using the DED method.
\end{abstract}

Keywords: Additive technology, direct energy deposition, repair, powder metallurgy, automated production

\section{INTRODUCTION}

Metal components of machine-building production usually have a certain set of parameters that are subject to high property requirements. There is an abrasion or cracking of the working parts of the mechanism during the operation of the product or tooling. When the resource is depleted, it is necessary to make a full replacement or repair of the used parts. If a part is made of high-alloyed high carbon steel and has a complex geometry, then the replacement of such a unit has a high cost due to its high mechanical properties, that which requires the use of special machining tools for hard materials, then, as a rule, heat treatment is needed for surface hardening. An example of such products may be molds, shafts, tools.

Today, there are already methods for repairing metal products that can be called classic: electric arc welding and plasma surfacing [1-3]. These technologies are well suited for coarse continuous processing of materials, but due to the large area of these processes, it is difficult to influence certain areas and repair them with great accuracy.

A new class of technologies is being actively introduced into the modern industry - additive technology, with the help of which it is possible not only to manufacture products from scratch, but also to repair and restore worn out and damaged elements. In particular, the method of direct energy deposition (DED) allows you to apply layers of metal on the surface of the part, restoring the original geometry. The essence of the DED method is to directly feed a metal powder or composite powder mixture into a molten bath formed by a laser beam [4-6]. The local action of heating the laser beam, the selective effect, as well as the high accuracy of modern robotic manipulators allow using this technology as an advanced and modern method for repairing and restoring products. An example of the application of DED technologies for the restoration of milling grooves made of powder steel, as well as a Ti-6Al-4V titanium coating, is reviewed in [7]. The authors did not find significant heat-affected zone. In [8], the result of turbine blade recovery was presented using this method, where the authors showed a successful repair result, and also gave an estimate of energy savings of $36 \%$ when the turbine blade was restored using the DED method compared to creating a new one. In [9], the possibility was studied, and the effectiveness of using this method for restoring worn walls of weapon barrels 
under the influence of erosion was also shown. As a material for repair in the described work, TiC powder was used, which showed high performance properties when surfacing a weapon barrel.

It was experimentally found that when surfacing new metal layers on the prepared die section in order to restore the original geometry, small cracks appeared on the die surface in the area close to the deposition point. The photograph of such cracks is shown in the Figure 1.

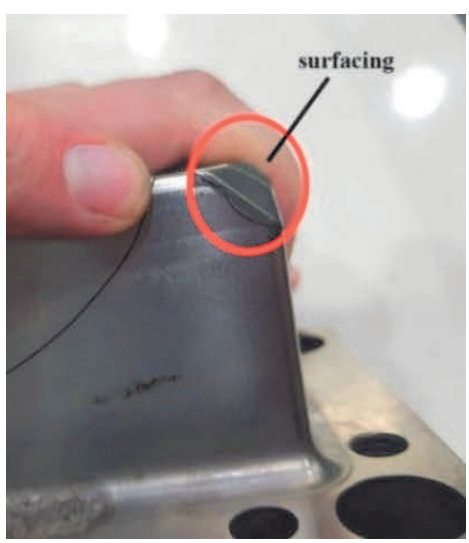

Figure 1 Cracks in the surfacing area

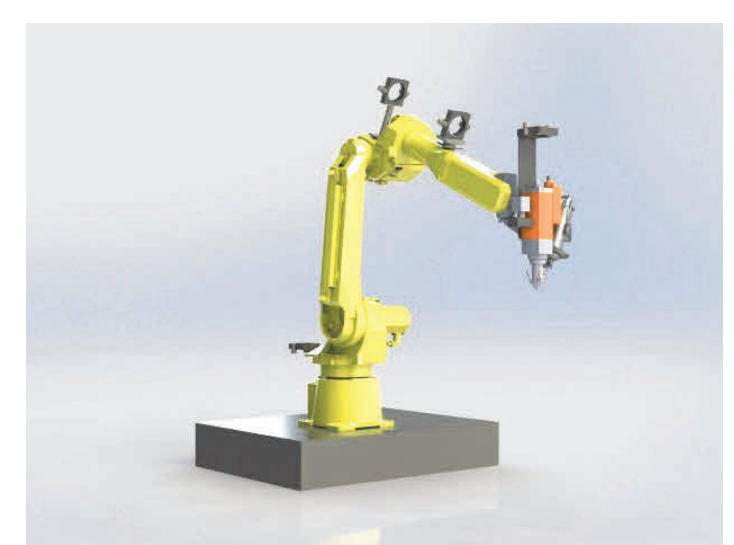

Figure 2 6-axis robot with a surfacing head for the implementation of DED technology

The reason for the formation of such cracks is presumably intergranular corrosion, which is a frequent problem in the processes of welding and surfacing [10,11]. This defect appears due to the release of carbides along the grain boundaries as a result of overheating of the punch during the deposition process above $700{ }^{\circ} \mathrm{C}$ for a long time. There are several ways to solve this problem. The first is to use the low-energy flow mode, that is, use small surfacing speeds, use a thin laser beam and increase the airflow in the working area. This method is not suitable due to low productivity. The second method involves reducing the temperature gradient throughout the die volume, which can be achieved by preheating, for example, in a muffle furnace. From a technological point of view, the latter method is the simplest to implement, since the main task is reduced to the selection of the preheating temperature. This method was chosen. There is also a method of applying an intermediate buffer layer of ductile metal, which is deposited before the base metal is deposited. This method has its advantages, but it is difficult to say how its application will affect the performance properties, so this requires separate studies.

This article explores the possibility of repairing and restoring a die from Japanese steel SKD11 with a carbon content of C $1.65 \%$, and chromium $\mathrm{Cr} 11.5 \%$ (in wt.\%) using preheating in a muffle furnace. AISI H13 die tool steel was chosen as the material that replaces the worn parts of the die. This steel contains carbon $\mathrm{C}$ in the amount of $0.44 \%$ and the main alloying element is chromium $\mathrm{Cr} 5.5 \%$ (in wt.\%).

\section{METHODOLOGY AND EXPERIMENT}

The surfacing of the metal powder of the brand AISI H13 with a particle size of 45 - 150 microns was carried out on the installation of the DED, developed by the St. Petersburg Polytechnic University. The main components of this apparatus are a robotic manipulator, a filler head and an ytterbium fiber laser (Figure 2).

Since DED is a related welding process, the required heating temperature was calculated based on the carbon equivalent using formula (1), the calculation of which is given in the Séférian book [13].

Ceqv $=C+\frac{M n+C r}{9}+\frac{N i}{18}+\frac{7 M o}{90}$ 
where: Ceqv - carbon equivalent, dimensionless quantity. C, Mn, $\mathrm{Cr}, \mathrm{Mo}, \mathrm{V}, \mathrm{Ni}, \mathrm{Cu}$ - share of chemical elements (wt.\%). Then, using the Séférian formula (2), the temperature was calculated based on the values of the carbon coefficient and the thickness of the product.

$T=350 \sqrt{ }(\mathrm{C}-0,25)$

where: $\mathrm{T}$ is preheat temperature, ${ }^{\circ} \mathrm{C}, \mathrm{C}$ - Séférian equation, dimensionless quantity, where:

$\mathrm{C}=\operatorname{Ceqv}(1+0,005 a)$

a - the average wall thickness, $\mathrm{mm}$

Since the calculated temperature obtained for the die material turned out to be too high (more than $600{ }^{\circ} \mathrm{C}$ ), which is explained by a high proportion of carbon, heating to this temperature will have an unacceptable effect on the heat-treated structure of the entire stamp, and hence on its hardness. It was taken to limit the temperature to $400^{\circ} \mathrm{C}$, based on the experience of welding high-carbon steels.

Before surfacing, the die was placed in a muffle furnace and heated with the furnace to $400{ }^{\circ} \mathrm{C}$ for 1 hour, followed by holding for 10 minutes. After heating, the die was placed on a heat-insulated tilt-turn table and a surfacing process was included with a pre-written program based on a CAD model. After the DED process, the die with the weld metal volume was cooled together with the furnace from $400{ }^{\circ} \mathrm{C}$ to room temperature. The result obtained before surfacing and after surfacing is presented in Figure 3.

a)

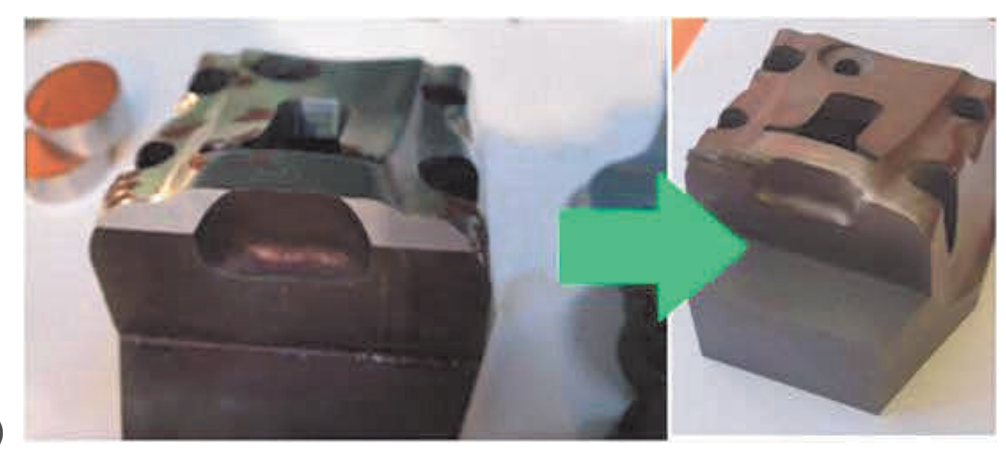

b)

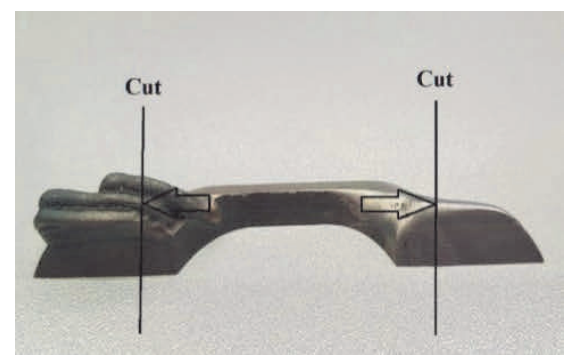

Figure 3 The die before repair and after repair by the DED method a), areas of a cut for research of material structure. The first area before milling, the second zone after milling b)

Since after the surfacing operation it is supposed to use the milling of excess material, then, as can be seen from Figure $\mathbf{3 a}$ and Figure $\mathbf{3 b}$, the surfacing was carried out with a stock of material. Also, since on the die that we restored, there were 2 corners on which surfacing was performed, one of the corners was machined with a mill, and the other one was not. It was necessary to track the structure in the final finished material and in the material only after surfacing. The weld area together with part of the die presented is in Figure $\mathbf{3 b}$.

amples were pressed and then chemical etching was performed in a solution of $20 \mathrm{ml}$ of methyl alcohol, $3 \mathrm{ml}$ of nitric acid $\mathrm{HNO}_{3}$ and $9 \mathrm{ml}$ of hydrochloric acid $\mathrm{HCl}$ for 1 minute.

The study of the structure was carried out using an optical microscope "Leica DMI 5000". The hardness measurement was carried out in HRC units using a hardness tester "Zwick/Roell ZHU". The study of the gradient transition in chemical composition was carried out using energy dispersive analysis on a scanning electron microscope (SEM) "TESCAN Mira 3 LMU".

\section{RESULT AND DISCUSSION}

The structure of the deposited material ASIS H13 obtained with an optical microscope is shown in Figure 4. 
a

b

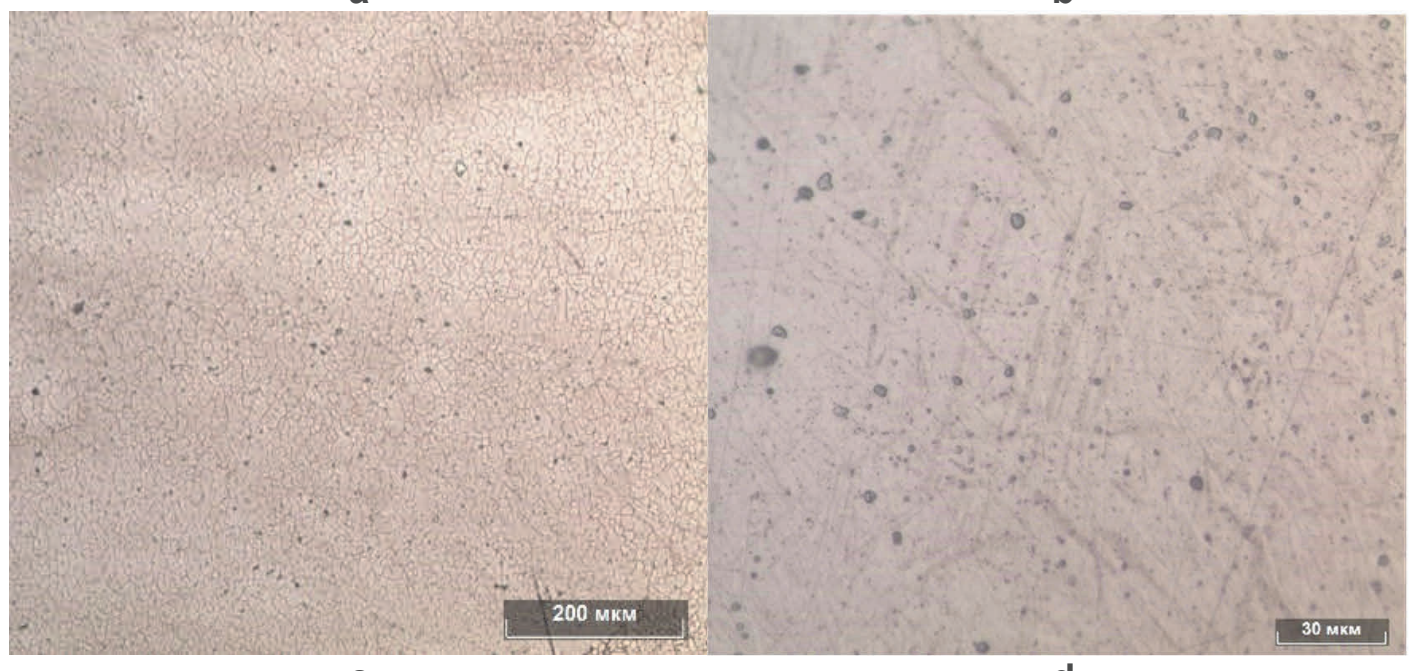

C

d
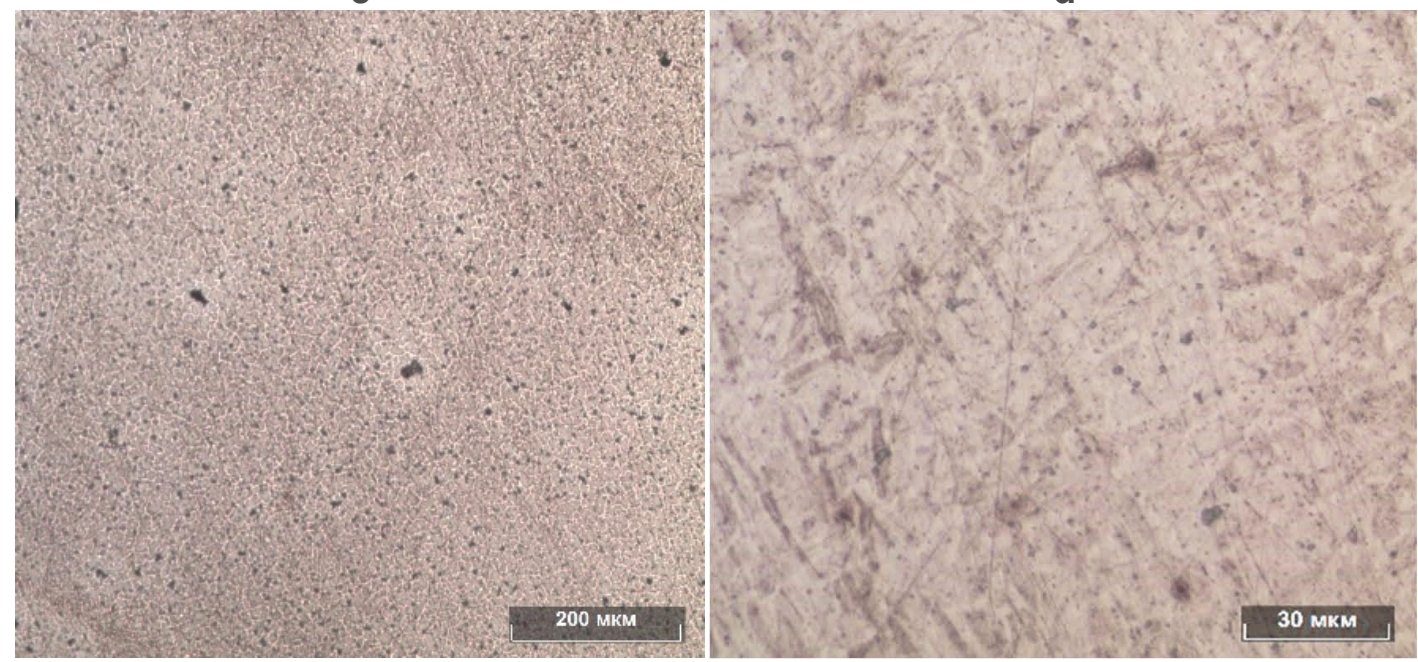

Figure 4 Structure of the built-up material ASIS H13, where a - sample after machining, b - sample after machining - fivefold magnification than in case a), c - sample before machining, $d$ - sample before machining - fivefold magnification than in case c.

The main structure of the material after the restoration of the stamp is grain with a grain size of about 10 microns. Also in the cladding without machining (Figure 4, d) there are areas that consist of tempered martensite needles, which are a ferritic-carbide mixture. The needle structure in the sample with final processing is practically absent. Apparently, in the processed part, this structure was not found due to the fact that as a result of mechanical processing, additional heating occurred, contributing to the processes of decomposition. Further, the structure of the transitional heat-affected zone between the two materials was studied, where on top is AISI H13 steel, on the bottom is SKD11 steel, the results are presented in Figure $\mathbf{5}$. Since no differences were found in the structure for the two samples, photographs are presented only for the sample after machining. As can be seen from Figure 5, there is a region with a transitional structure between the two steels (heat affected area) and in this region the highest hardness is noted compared with the basic material of the punch and shell that will be shown later. Hardness was measured in four zones as shown in Figure 6.

According to the results of measuring the hardness, it is clear that the total hardness of the two materials is approximately the same, but it was also noted that the hardness at the boundary in the heat-affected zone reaches the highest values of $57 \mathrm{HRC}$, and the average hardness of the weld material is $53 \mathrm{HRC}$. This 
hardness is satisfactory for this product, but still this value is rather low. As a recommendation, it is possible to suggest surface hardening, or, in the process of surfacing, to use increased cooling conditions to obtain a large proportion of martensitic structure in the AISI H13 surfacing steel.

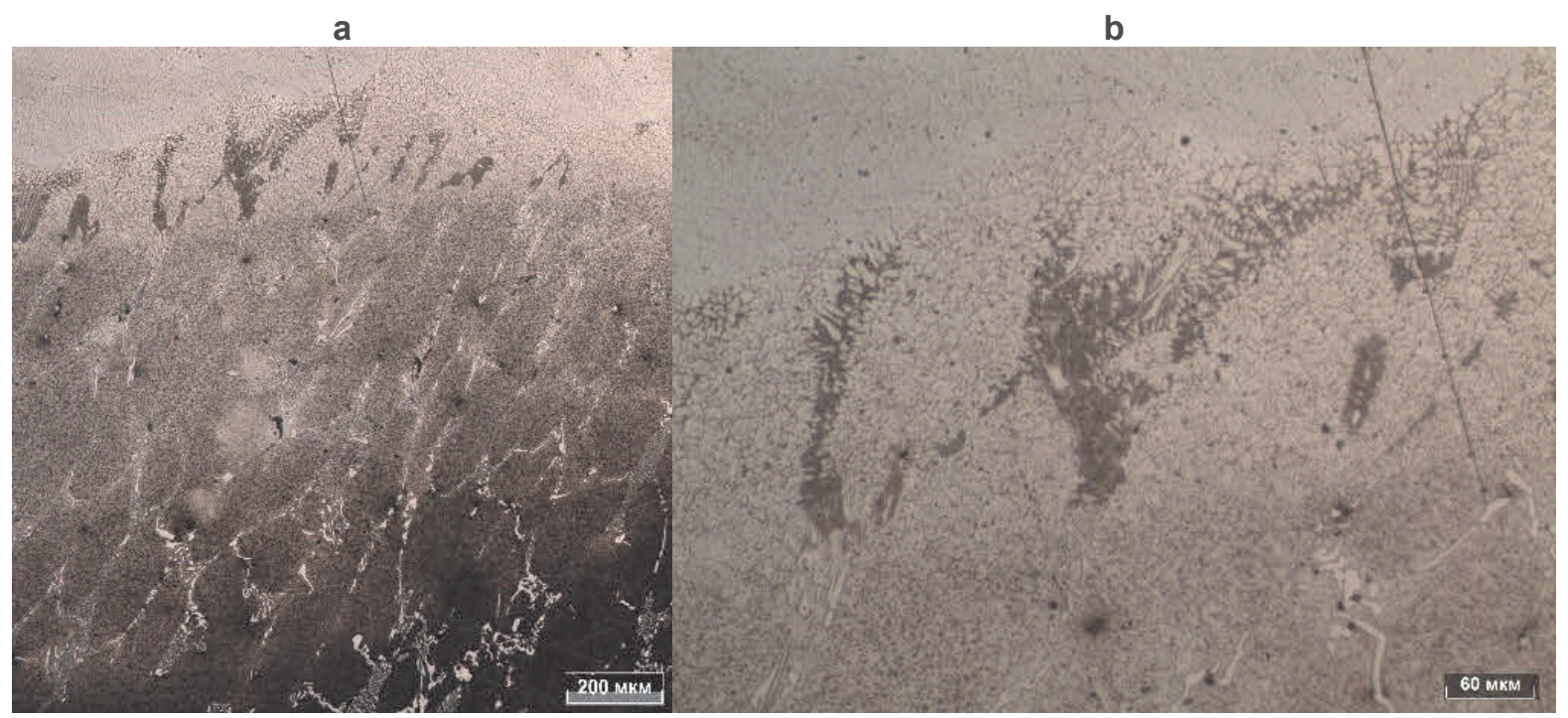

Figure 5 Heat-affected area, a - lower magnification, b - double magnification than in case a

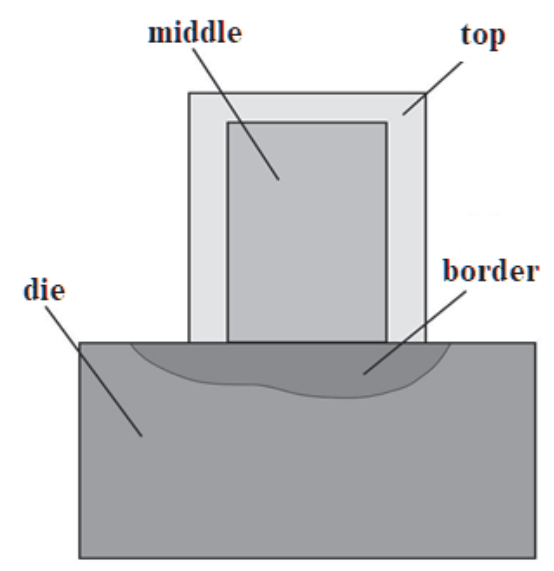

Figure 6 Hardness measurement areas

The results of Rockwell hardness measurements in HRC are presented in a histogram (Figure 7).

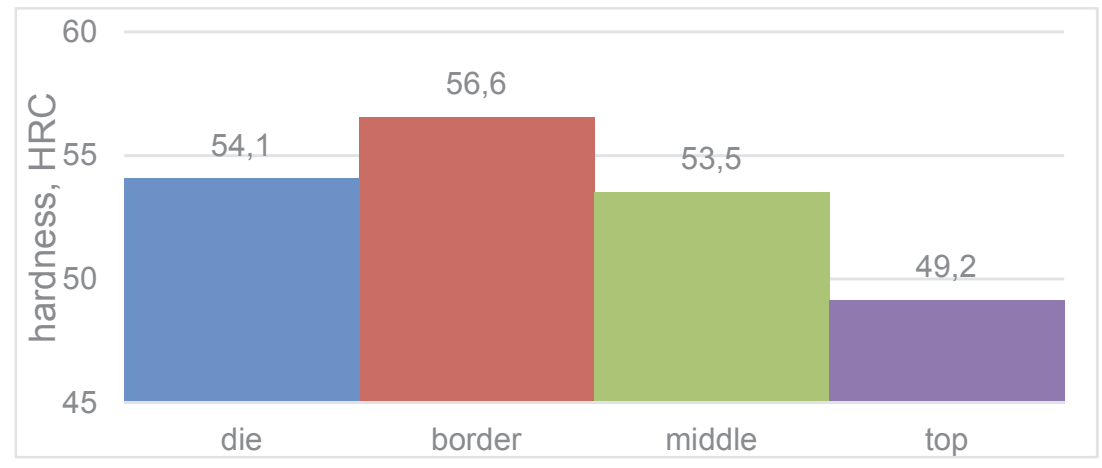

Figure 7 Hardness values in different areas of the sample 


\section{CONCLUSION}

The geometry of a high-carbon steel SKD11 die was successfully restored using the DED method by surfacing AISI H13 steel powder. As a result of microstructural analysis on an optical microscope, thermal stress cracks were not detected, and there were not cracks on the surface of the die itself even after mechanical processing. The hardness value in the repaired die area is satisfactory, but not optimal for this type of product. Therefore, it is recommended to try to increase this parameter using more intense thermal effects. It is shown that the DED method can be used for automated local restoration of worn-out parts of a product with high accuracy using a CAD model.

\section{REFERENCES}

[1] WAHAB, M.A. and PAINTER, M.J. The prediction of the temperature distribution and weld pool geometry in the gas metal arc welding process. Journal of Materials Processing Technology. 1998. vol. 77, no. 1-3, pp. 233-239.

[2] SU, C.Y., CHOU, C.P., WU, B.C. and LIH, W.C. Plasma transferred arc repair welding of the nickel-base superalloy IN-738LC. Journal of Materials Engineering and Performance [online]. 1997. vol. 6, no. 5, pp. 619-627.

[3] WU, .S., WAN, L., REN, W..J. and ZHANG, X.Y. Plasma arc welding: Process, sensing, control and modeling. Journal of Manufacturing Processes [online]. 2014. vol. 16, no. 1. pp. 74-85.

[4] MASAYLO, D.V., POPOVICH, A.A., SUFIYAROV, V.SH., ORLOV, A.V. and SHAMSHURIN, A.I. A Study of Structural Features of a Gradient Material from a Heat-Resistant Nickel Alloy Produced by Laser Cladding. Metallovedenie i Termicheskaya Obrabotka Metallov. 2018. vol. 761, no. 11, pp. 53-58.

[5] SCHWENDNER, K.I., BANERJEE, R., COLLINS, P.C. and BRICE, C.A. Direct laser deposition of alloys from elemental powder blends. Scripta Materialia [online]. 2001. vol. 45, no. 10. pp. 1123-1129.

[6] LEYENS, C. and BEYER, E. Innovations in laser cladding and direct laser metal deposition. Laser Surface Engineering. 2015. pp. 181-192.

[7] GRAF, B., GUMENYUK, A. and RETHMEIER, M. Laser Metal Deposition as Repair Technology for Stainless Steel and Titanium Alloys. Physics Procedia. 2012. vol. 39, pp. 376-381.

[8] WILSON, M.J., PIYA, C., SHIN, Y.C., ZHAO, F. and RAMANI, K. Remanufacturing of turbine blades by laser direct deposition with its energy and environmental impact analysis. Journal of Cleaner Production. 2014. vol. 80. pp. 170-178.

[9] NOWOTNY, S., SPATZIER, J., KUBISH, F., SCHAREK, S., ORTNER, J. and ECKHARD, B. Repair of Erosion Defects in Gun Barrels by Direct Laser Deposition. Journal of Thermal Spray Technology [online]. 2012. vol. 21. no. 6, pp. 1173-1183.

[10] TEDMON, C. S., VERMILYEA, D. A and ROSOLOWSKI, J. H. Intergranular corrosion of austenitic stainless steel. The Electrochemical Society. 1971. Vol. 118, no. 2, pp. 192-202.

[11] PAN, Q.Y., HUANG, W.D., SONG, R.G., ZHOU, Y.H. and ZHANG, G.L. The improvement of localized corrosion resistance in sensitized stainless steel by laser surface remelting. Elsevier B.V. 1998. vol. 102, no. 3, pp. 245255.

[12] British Standart. Hot rolled products of structural steels - Part 1: General technical delivery conditions. British Standard EN 10025-1:2004. Available from: https://members.marticonet.sk/jkuba/normy/EN\%2010025-12004BS_HotRolledProducts_TDP.pdf

[13] SEFERIAN, D. Nauka o kovech ve svařování oceli. 1st. ed. Praha: SNTL, 1962. p. 422. 